\title{
Aberrantly upregulated FAM83H-AS1 facilitates malignant progression of esophageal squamous cell carcinoma
}

\author{
LIJIA BU* ${ }^{*}$, RONG WANG*, PINGPING LIU and JIE DA \\ Department of Oncology, The First Affiliated Hospital of Anhui Medical University, Hefei, Anhui 230022, P.R. China
}

Received December 13, 2019; Accepted May 21, 2020

DOI: 10.3892/ol.2020.12231

\begin{abstract}
The biological roles of the newly identified long non-coding RNA family with sequence similarity 83 member $\mathrm{H}$ antisense 1 (FAM83H-AS1) in esophageal squamous cell carcinoma (ESCC) have remained largely elusive. In the present study, it was determined that, in comparison with paired para-tumorous tissues or normal esophageal epithelial cells, FAM83H-AS1 expression in cancer tissues and cell lines was markedly upregulated. Furthermore, FAM83H-AS1 expression was significantly elevated in patients with ESCC and lymph node metastasis or a late TNM stage, while no association with any other clinicopathological characteristics was detected. Furthermore, the overall and disease-free survival, as assessed by the Kaplan-Meier method, were significantly shortened in patients with high FAM83H-AS1 expression. A functional study then uncovered that knockdown of FAM83H-AS1 significantly suppressed the proliferation and migration of ESCC cells. The present results suggested that FAM83H-AS1 may facilitate the malignant progression of ESCC and may be utilized as a prognostic predictor and possibly a novel therapeutic target in ESCC that warrants further exploration.
\end{abstract}

\section{Introduction}

The incidence of esophageal cancer has been exhibiting annual increases $(1,2)$ and it is among the top five causes of cancer-associated death worldwide (1-3). In Asia, the majority of esophageal cancer cases are diagnosed pathologically as esophageal squamous cell carcinoma (ESCC) $(1,3,4)$. Multidisciplinary interventions, including surgery, chemotherapy and/or radiotherapy, are recommended for ESCC

Correspondence to: Dr Jie Da, Department of Oncology, The First Affiliated Hospital of Anhui Medical University, 13 Sanli'an Street, Hefei, Anhui 230022, P.R. China

E-mail:dj_ayfy@163.com

*Contributed equally

Key words: esophageal cancer, FAM83H-AS1, long non-coding RNA, biomarker according to the tumor stage (5). Despite the rapid progression in therapeutic methods, less than one in five ESCC patients survived after five years (1,4-6). Increasing evidence demonstrates that several genetic and epigenetic alterations contribute to the carcinogenesis of $\operatorname{ESCC}(5,7,8)$. The identification of novel targets to develop therapeutic strategies is of vital importance to improve the survival of ESCC patients.

Several studies focusing on human malignancies have indicated dysregulation of the recently discovered long non-coding RNAs (lncRNA), which do not give rise to functional proteins (9-11). LncRNAs were indicated to exhibit multifaced functions in important biological processes, including cell growth, apoptosis, embryonic development and tumorigenesis, by downregulating or upregulating protein expression at the chromatin organization, epigenetic control, and transcriptional and posttranscriptional levels $(9,12-16)$. Numerous lncRNAs have been indicated to be significantly dysregulated in human tumors and may be ideal candidates for prognostic markers (17-20). Li et al (21) proposed a three-lncRNA panel composed of ENST00000435885.1, XLOC_013014 and ENST00000547963.1 that may be used to predict the survival of patients with esophageal cancer patients. Upregulated metastasis-associated lung adenocarcinoma transcript 1 predicts poor prognosis in several human cancer types, including ESCC (21-24).

Family with sequence similarity 83 member $\mathrm{H}$ antisense 1 (FAM83H) is an lncRNA of 12,198 nucleotides in length whose encoding gene is located in the antisense region of FAM $83 \mathrm{H}$ and which has been indicated to promote tumor progression. Several studies have identified FAM83H-AS1 as an oncogenic factor in bladder cancer (25), intestinal malignancies (26,27), lung adenocarcinoma (28) and pancreatic ductal adenocarcinoma (29). Zhang et al (28) indicated that upregulated FAM83H-AS1 promoted proliferation by activating the MET/EGFR signaling pathway in lung cancer. Furthermore, by blocking the NOTCH pathway, knockdown of FAM83H-AS1 suppressed the proliferation of colorectal cancer cells (26). In a recent study using several datasets, FAM83H-AS1 was indicated to be involved in the regulation of the transcriptional profile of pancreatic tumor samples and cell lines (29). However, the expression levels and roles of FAM83H-AS1 in ESCC have so far remained to be determined. Considering its crucial role in tumor pathogenesis, the present study aimed to explore associations of FAM83H-AS1 with ESCC. 
The present study suggested that, in comparison with paired para-tumorous tissues or normal esophageal epithelial cells, FAM83H-AS1 expression in cancer tissues and cells was markedly upregulated. High expression of FAM83H-AS1 was observed in patients with the presence of metastasis to the lymph nodes and an advanced tumor stage. Furthermore, high FAM83H-AS1 expression was indicated to predict poor overall and disease-free survival in patients with ESCC. Cell proliferation and Transwell migration assays confirmed that FAM83H-AS1 facilitated the malignant progression of ESCC. These results indicated that FAM83H-AS1 may be used as a prognostic marker and a novel therapeutic target in ESCC.

\section{Materials and methods}

Tissue samples and clinical data collection. In the present study, 134 patients with ESCC who did not undergo any neoadjuvant anti-tumor therapy were enrolled. Surgery of enrolled subjects was performed at the First Affiliated Hospital of Anhui Medical University (Hefei, China) between March 2007 and August 2010. All diagnoses were confirmed by professional pathological evaluation. The clinicopathological characteristics of the patients with ESCC retrieved from their medical records are presented in Table I. Dissected tissue samples were immediately soaked in RNAlater ${ }^{\circledR}$ solution (Beyotime Institute of Biotechnology) prior to careful preservation in an ultra-low temperature freezer $\left(-80^{\circ} \mathrm{C}\right)$ following a standard procedure.

Cell culture. A total of 4 ESCC cell lines (KYSE410, KYSE510, KYSE520 and KYSE30) were purchased from Deutsche Sammlung von Mikroorganismen und Zellkulturen (DSMZ, Braunschweig, Germany, https://www.leibniz-gemeinschaft. de/institute/leibniz-institute-alle-listen/leibniz-institut-dsmz-deu tsche-sammlung-von-mikroorganismen-und-zellkulturen-gmbh. $\mathrm{html}$ ). All cells were cultured according to a previous protocol (30) and tested for mycoplasma infection prior to use. The medium for NE1 esophageal epithelial cells (DSMZ) was mixed with an equal amount of defined keratinocyte serum-free medium (cat. no. 10744019; Gibco, Thermo Fisher Scientific, Inc.) with growth supplements and EpLife medium with $60 \mu \mathrm{M}$ calcium (cat. no. MEPI500CA; Gibco; Thermo Fisher Scientific, Inc.).

RNA isolation and reverse transcription-quantitative PCR $(R T-q P C R)$. RNA extraction was performed according to standard protocols with TRIzol reagent (Invitrogen; Thermo Fisher Scientific, Inc.). The extracted products $(1 \mu \mathrm{g})$ were then subjected to RT in order to obtain complementary DNA using random primers with the Prime Script RT Reagent Kit (Takara Bio, Inc.). The SYBR Premix Taq (Promega Corp.) kit was used to determine the expression levels of specific genes in the qPCR assays. The $2^{-\Delta \Delta \mathrm{Cq}}$ method (30) was used to quantify the relative expression of FAM83H-AS1. The primers had the following sequences: FAM83H-AS1 forward, 5'-TCCTCA AGCAAAGCACTC-3' and reverse, 5'-TACGGCAGAAAG AACCAA-3'; GAPDH forward, 5'-GGAGCGAGATCCCTC CAAAAT-3' and reverse, 5'-GGCTGTTGTCATACTTCT CATGG-3'.

Small interfering (si)RNA transfection. The cells $\left(4 \times 10^{5}\right.$ cells/well) were seeded in the 6 -well plate on the day prior to transfection with Lipofectamine 2000 (Thermo Fisher Scientific, Inc.). In brief, siRNA (5 $\mu \mathrm{l} /$ well) and Lipofectamine 2000 (5 $\mu \mathrm{l} /$ well) were individually incubated with $125 \mu$ l Opti-Minimum Essential Medium (MEM; Gibco; Thermo Fisher Scientific, Inc.) at room temperature for $5 \mathrm{~min}$. They were then mixed and incubated at room temperature. After $20 \mathrm{~min}$, the mixture was added into the culture medium according to the manufacturer's protocol. At two days after transfection, the cells were collected for RT-qPCR, MTS and Transwell assays. The sequences of siRNAs targeting FAM83H-AS1 (si\#FAM83H-AS1) and the scrambled control siRNAs (NC) were as follows: si\#FAM83H-AS1: 5'-GCTGAA TCACGTCAAGTAT-3', and NC: 5'-TTCTCCGAACGTGTC ACGT-3'.

MTS assay. The cell proliferation was measured with an MTS kit (Promega Corp.). In brief, $100 \mu \mathrm{l}$ suspension containing 500 cells was added to each well of a 96-well plate. At the indicated time-points, $10 \mu \mathrm{l}$ MTS was added to each well, followed by additional incubation for $2 \mathrm{~h}$ at $37^{\circ} \mathrm{C}$. The absorbance was measured at $450 \mathrm{~nm}$ (SpectraMax ${ }^{\circledR}$ M5 Multi-Mode Microplate Reader; Molecular Devices LLC) following gentle agitation for $10 \mathrm{~min}$. All assays were performed in three independent experiments and each condition was assessed in triplicate.

Transwell migration assay. To evaluate the migration capability, ESCC cells in the exponential growth phase were collected, washed with PBS, resuspended in serum-free medium and $200 \mu \mathrm{l}$ of this suspension containing $1 \times 10^{5}$ cells was added to the top of the $8 \mu \mathrm{m}$ chamber (BD Biosciences). The lower compartment was filled with $500 \mu$ l fetal bovine serum (Gibco; Thermo Fisher Scientific, Inc.). After $24 \mathrm{~h}$ of culture at $37^{\circ} \mathrm{C}$, the migrated cells were fixed with methanol for $15 \mathrm{~min}$ at room temperature, stained with $0.1 \%$ crystal violet for $30 \mathrm{~min}$ at room temperature and counted under a microscope. All assays were performed in triplicate.

Statistical analysis. SPSS (version 19.0; IBM Corp.) and GraphPad Prism 6.0 (GraphPad, Inc.) were used to perform statistical analysis and graph plotting, respectively. The Kaplan-Meier method was utilized to produce survival curves, while log-rank tests were used to calculate the P-values. Univariate and multivariate Cox models including hazard ratios and $95 \%$ confidence intervals were constructed in SPSS. An unpaired Student's t-test and the Chi-squared test were used to determine the significance of the differences between groups. $\mathrm{P}<0.05$ was considered to indicate a significant difference.

\section{Results}

General patient characteristics. In the present cohort, the percentage of male patients with ESCC was $77.6 \%$ and the median age was 60.0 years (age range, $36.0-88.0$ years). The number of subjects diagnosed as having stage I, II and III ESCC was $5(3.7 \%), 66(49.3 \%)$ and $63(47.0 \%)$, respectively. More than half of the patients (73/134) had lymph node metastasis (Table I).

Upregulation of FAM83H-AS1 in ESCC cancer tissues and cells. The expression of FAM83H-AS1 in ESCC samples 
Table I. Association between clinicopathological parameters and FAM83H-AS1 expression.

\begin{tabular}{|c|c|c|c|}
\hline \multirow[b]{2}{*}{ Variable } & \multicolumn{2}{|c|}{$\begin{array}{c}\text { FAM83H-AS1 } \\
\text { expression }\end{array}$} & \multirow[b]{2}{*}{ P-value } \\
\hline & Low & High & \\
\hline Age (years) & & & 1.000 \\
\hline$<60$ & $37(55.2)$ & $37(55.2)$ & \\
\hline$\geq 60$ & $30(44.8)$ & $30(44.8)$ & \\
\hline Sex & & & 0.836 \\
\hline Male & $51(76.1)$ & $53(79.1)$ & \\
\hline Female & $16(23.9)$ & $14(20.9)$ & \\
\hline Tumor size $(\mathrm{cm})$ & & & 0.342 \\
\hline$<5$ & $59(88.1)$ & $54(80.6)$ & \\
\hline$\geq 5$ & $8(11.9)$ & $13(19.4)$ & \\
\hline Degree of differentiation & & & 0.146 \\
\hline Well or moderate & $56(83.6)$ & $48(71.6)$ & \\
\hline Poor & $11(16.4)$ & $19(28.4)$ & \\
\hline Lymph node metastasis & & & $<0.001$ \\
\hline Present & $25(37.3)$ & $48(71.6)$ & \\
\hline Absent & $42(62.7)$ & $19(28.4)$ & \\
\hline TNM stage & & & $<0.001$ \\
\hline I-II & $49(73.1)$ & $22(32.8)$ & \\
\hline III & $18(26.9)$ & $45(67.2)$ & \\
\hline
\end{tabular}

Values are expressed as n (\%). FAM83H-AS1, family with sequence similarity 83 member $\mathrm{H}$ antisense 1 .

was first detected. As presented in Fig. 1A, FAM83H-AS1 was significantly upregulated in ESCC vs. adjacent epithelial tissues $(\mathrm{P}=0.0007)$. FAM83H-AS1 expression levels were then evaluated in ESCC cell lines and the results demonstrated that in KYSE410, KYSE510, KYSE520 and KYSE30 cells, FAM83H-AS1 was significantly upregulated compared with that in NE1 (Fig. 1B; $\mathrm{P}<0.05$ ).

Associations between FAM83H-AS1 expression levels and clinicopathological parameters. To characterize FAM83H-AS1 expression in ESCC, the fold change value, which indicates differences in expression ratios, was utilized. The median fold change value was considered as the cutoff. The association of FAM83H-AS1 with clinicopathological indices was analyzed (Table I). Patients with metastasis to lymph nodes or advanced TNM stage tended to have high expression of FAM83H-AS1 (Table I). However, no obvious associations of FAM83H-AS1 with other clinicopathological characteristics, including age, gender and degree of differentiation, were observed (Table I).

Association between FAM83H-AS1 expression and survival in ESCC. It was then analyzed whether FAM83H-AS1 may be used as a prognostic predictor in ESCC. The expression of FAM83H-AS1 in the cancer tissues was profiled and the median fold change was 1.55 (Fig. 2A). The Kaplan-Meier method and the log-rank test were used for further survival
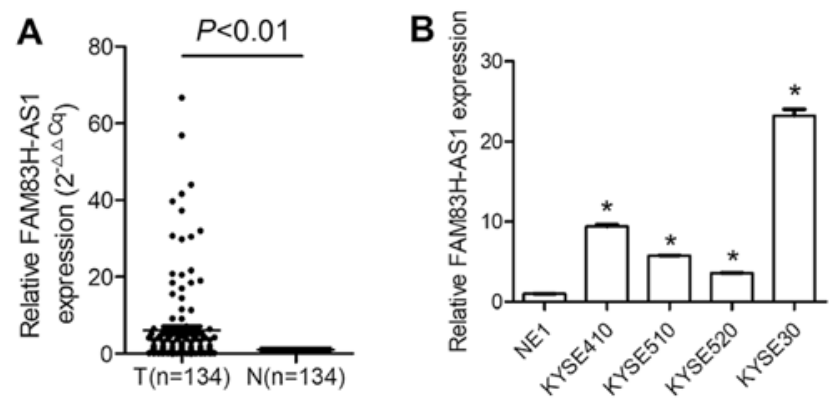

Figure 1. Aberrantly increased FAM83H-AS1 expression in ESCC. (A) FAM83H-AS1 in ESCC tissues $(n=134)$. Data are presented as $2^{-\Delta \Delta C q}$ values. (B) FAM83H-AS1 expression in the cancer cell lines KYSE410, KYSE510, KYSE520 and KYSE30, as well as the normal cell line NE1. Values are expressed as the mean \pm standard error of the mean. ${ }^{*} \mathrm{P}<0.05$. FAM83H-AS1, family with sequence similarity 83 member $\mathrm{H}$ antisense 1; ESCC, esophageal squamous cell carcinoma; T, tumor; N, normal.

analysis. As presented in Fig. 2B, the overall survival of patients with high FAM83H-AS1 expression was significantly worse than that of patients with low FAM83H-AS1 expression $(\mathrm{P}<0.0001)$. Furthermore, high expression of FAM83H-AS1 indicated poor disease-free survival of patients with ESCC $(\mathrm{P}=0.0095$; Fig. 2C). Univariate survival analyses suggested that a larger tumor size $(\mathrm{P}=0.030)$, presence of lymph node metastasis $(\mathrm{P}<0.001)$, advanced TNM stage $(\mathrm{P}<0.001)$ and upregulated FAM83H-AS1 expression $(\mathrm{P}<0.001)$ influenced the prognosis of patients with ESCC (Table II). Further multivariate analyses indicated that only the TNM stage $(\mathrm{P}<0.001)$ and FAM83H-AS1 expression $(\mathrm{P}=0.014)$ were independent predictors of overall (Table II).

Oncogenic roles of FAM83H-AS1 in vitro. The above results prompted us to further explore the function of dysregulated FAM83H-AS1 in ESCC. si\#FAM83H-AS1, as well as the NC were introduced into KYSE30 and KYSE510 cells with relatively high expression levels of FAM83H-AS1. The knockdown efficiency was confirmed by RT-qPCR analysis (Fig. 3A). MTS and Transwell assays revealed that knockdown of FAM83H-AS1 significantly inhibited cell proliferation (Fig. 3B) and decreased the migration capacity (Fig. 4A and B) of the ESCC cell lines KYSE30 and KYSE510. These data further suggested oncogenic roles of FAM83H-AS1 in ESCC.

\section{Discussion}

ESCC ranks among the top five causes of cancer-associated death in Eastern Asia, including China $(1,3,6)$. Therefore, identification of novel molecular candidates that may be used for the precise diagnosis and prognosis prediction remains an urgent requirement. The present study demonstrated marked overexpression of FAM83H-AS1 in ESCC compared with paired normal tissues. In addition, its expression in ESCC cell lines was significantly upregulated compared with that in the normal NE1 cell line. Furthermore, FAM83H-AS1 expression was associated with lymph node metastasis and the TNM stage. Of note, overexpression of FAM83H-AS1 was and independent predictor of poor overall survival of patients with ESCC and is thus an ideal candidate for a prognostic biomarker. 
Table II. Univariate and multivariate analyses of overall survival prognostic factors in patients with esophageal squamous cell carcinoma.

\begin{tabular}{|c|c|c|c|c|}
\hline \multirow[b]{2}{*}{ Factor } & \multicolumn{2}{|c|}{ Univariate analysis } & \multicolumn{2}{|c|}{ Multivariate analysis } \\
\hline & HR $(95 \%$ CI $)$ & P-value & $\mathrm{HR}(95 \% \mathrm{CI})$ & P-value \\
\hline Age $(\geq 60 /<60$ years $)$ & $1.46(0.91-2.33)$ & 0.117 & - & - \\
\hline Sex (male/female) & $0.93(0.54-1.61)$ & 0.799 & - & - \\
\hline Tumor size $(\geq 5 /<5 \mathrm{~cm})$ & $1.92(1.06-3.46)$ & 0.030 & $1.36(0.74-2.48)$ & 0.321 \\
\hline Differentiation (poor/well, moderate) & $1.57(0.93-2.64)$ & 0.091 & - & - \\
\hline Lymph node metastasis (present/absent) & $2.90(1.73-4.86)$ & $<0.001$ & $1.19(0.47-2.97)$ & 0.714 \\
\hline TNM stage (III/I-II) & $3.38(2.05-5.58)$ & $<0.001$ & $2.71(1.59-4.61)$ & $<0.001$ \\
\hline FAM83H-AS1 (high/low) & $2.68(1.64-4.39)$ & $<0.001$ & $1.93(1.14-3.25)$ & 0.014 \\
\hline
\end{tabular}

HR, hazard ratio; FAM83H-AS1, family with sequence similarity 83 member $\mathrm{H}$ antisense 1.
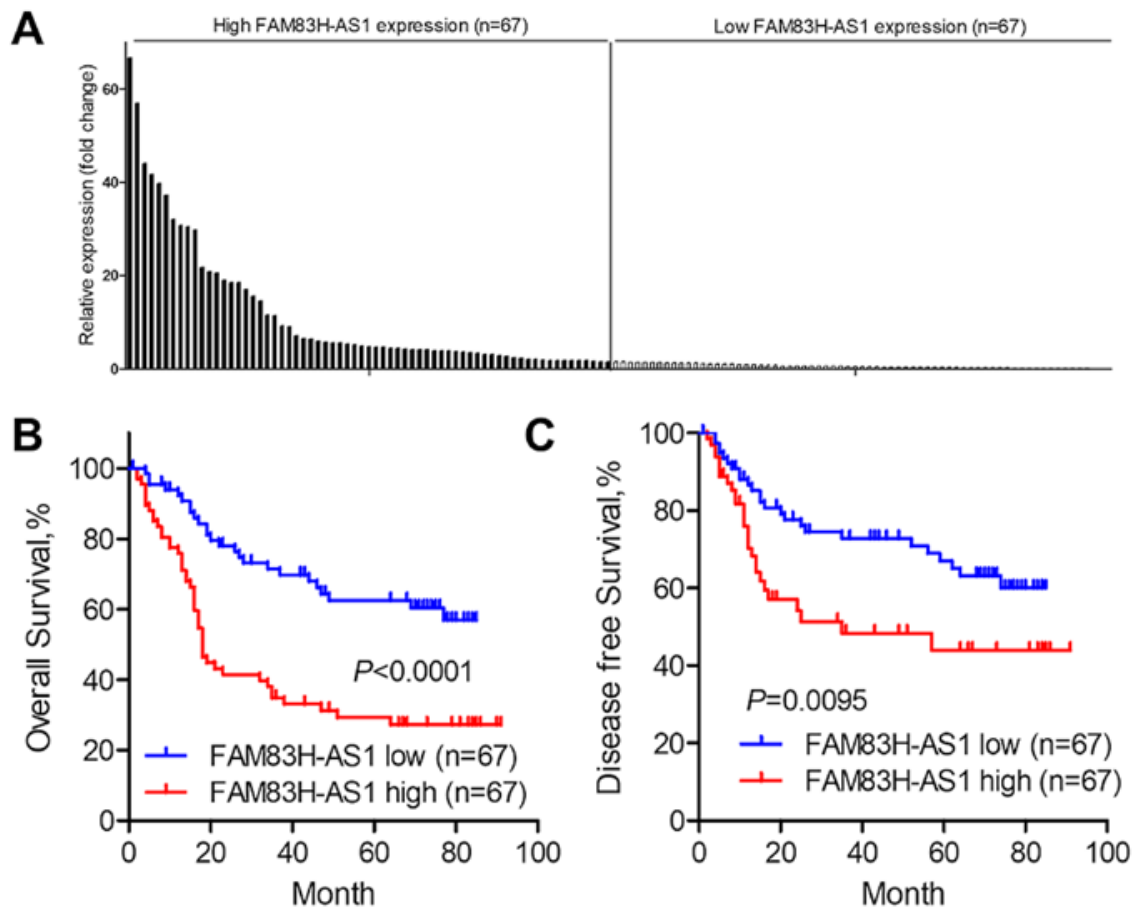

Figure 2. Prognostic value of upregulated FAM83H-AS1 in patients with ESCC. (A) FAM83H-AS1 levels in tumor samples and definition of high and low expression groups, using the median fold change as the cut-off value. (B) Kaplan-Meier curves for overall survival of patients with ESCC by FAM83H-AS1 levels $(\mathrm{P}<0.001)$. (C) Kaplan-Meier curves for disease-free survival in patients with ESCC by FAM83H-AS1 levels ( $\mathrm{P}=0.0095)$. '+', indicated censored datapoints; FAM83H-AS1, family with sequence similarity 83 member $\mathrm{H}$ antisense 1; ESCC, esophageal squamous cell carcinoma.

As evolutionally conserved molecules with tissue-specific expression $(13,15,16)$, IncRNAs have been reported to be involved in the pathophysiology of several human diseases, including cancer $(10,17,19,21,24)$. Dysregulation of lncRNA may exert tumor-suppressive or oncogenic characteristics and may be detected throughout the entire process of cancer development. For instance, Qi et al (31) indicated that by downregulating cyclin-dependent kinase-interacting protein 1 and cadherin 1, ArfGAP with GTPase domain, ankyrin repeat and $\mathrm{PH}$ domain 2-AS1 promotes stomach cancer progression. Chen et al (20) suggested that overexpressed HOTTIP in ESCC predicts poor prognosis. Silencing of HOTTIP attenuated malignant phenotypes including proliferation and invasion (20).
In the present study, a positive association between the upregulation of FAM83H-AS1 and metastasis to the lymph nodes was observed. Previous studies have indicated that downregulation of Notch1 signaling in tumor tissues contributed to lymph node metastasis and tumor-induced lymphangiogenesis of ESCC (32). Furthermore, overexpression of FAM83H-AS1 promoted the migration of SW480 and HT29 cells through modulation of the Notch pathway (26). In addition, microRNA (miR)-136, which was reported as a direct target of FAM83H-AS1 in breast cancer (33), was indicated to be associated with lymph node metastasis in ESCC (34). However, whether and how Notch signaling, miR-136 or other pathways mediate the oncogenic roles of FAM83H-AS1 in ESCC warrants further exploration. 

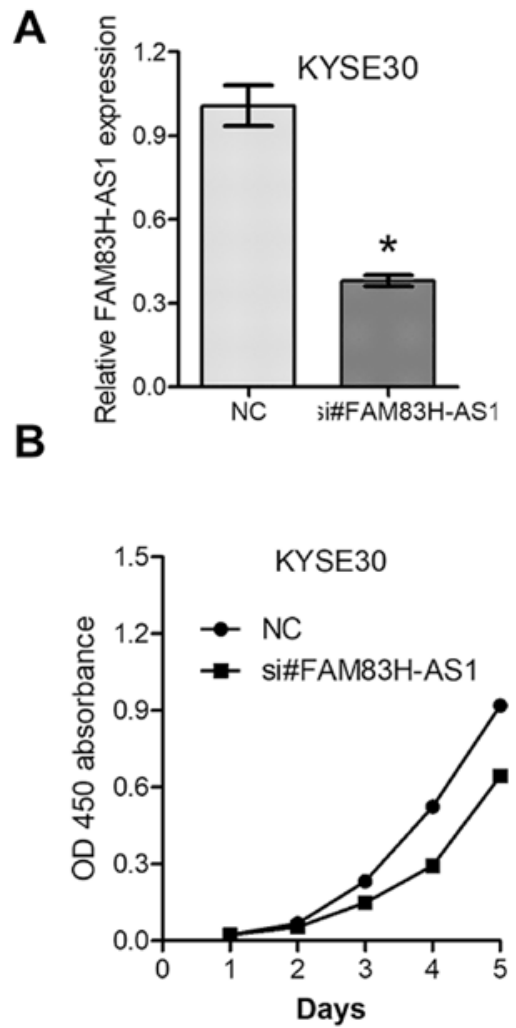
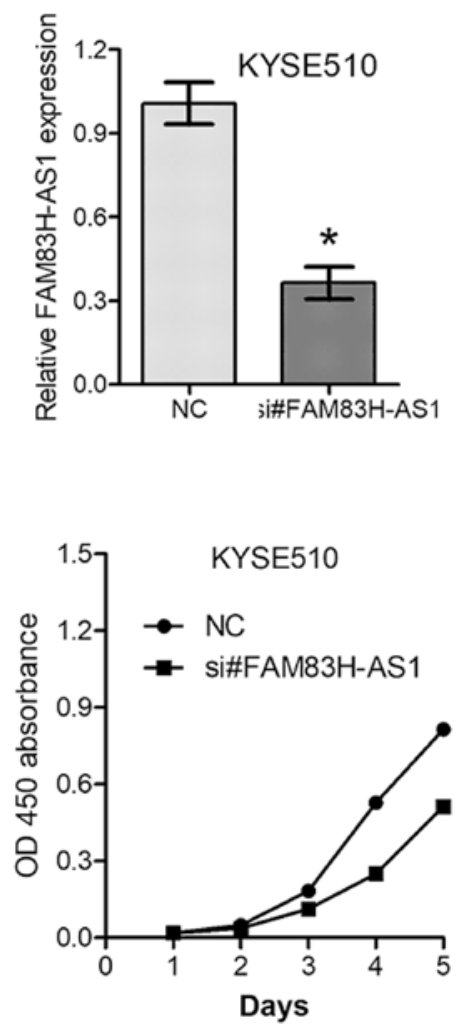

Figure 3. Proliferation assay of ESCC cells after knockdown of FAM83H-AS1. (A) FAM83H-AS1 level in KYSE30 and KYSE510 cells after knockdown. (B) Proliferation of ESCC cells after knockdown of FAM83H-AS1. ${ }^{*} \mathrm{P}<0.05$ determined with the unpaired Student's t-test. FAM83H-AS1, family with sequence similarity 83 member $\mathrm{H}$ antisense 1; ESCC, esophageal squamous cell carcinoma; OD 450, optical density at $450 \mathrm{~nm}$; NC, negative control; si, small interfering RNA.
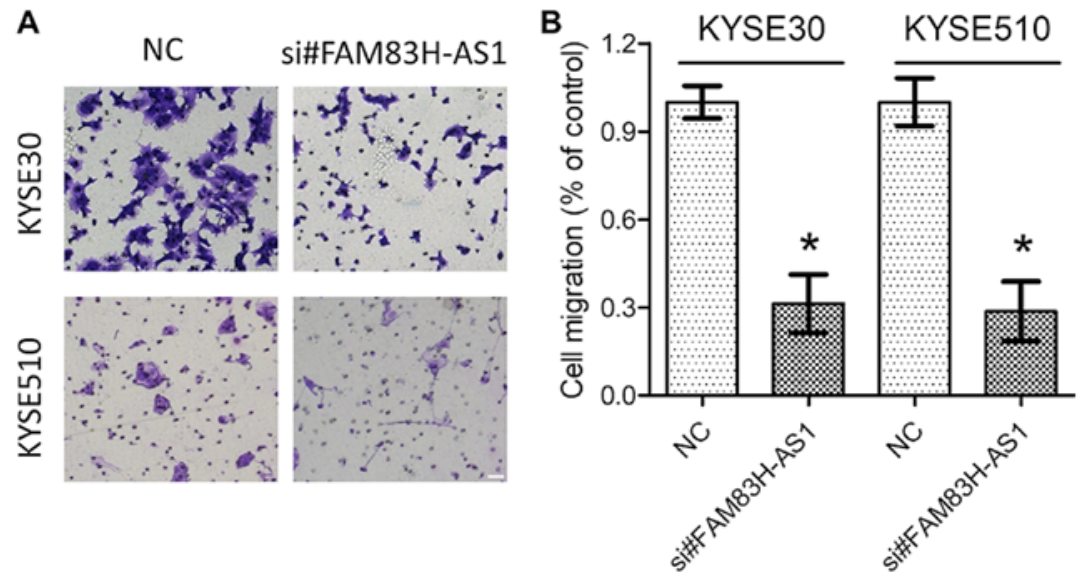

Figure 4. Migration assays of esophageal squamous cell carcinoma cells after knockdown of FAM83H-AS1. (A) Representative images of migrated cells (scale bar, $100 \mu \mathrm{m}$ ). (B) Quantification of cell migration after FAM83H-AS1 knockdown. "P<0.05 determined with the unpaired Student's t-test. FAM83H-AS1, family with sequence similarity 83 member $\mathrm{H}$ antisense 1; NC, negative control; si, small interfering RNA.

Several lines of evidence have suggested that upregulated FAM83H-AS1 predicted poor prognosis of malignant diseases, including bladder cancer (25), gastrointestinal cancer $(26,27,29)$, ovarian cancer (35) and lung cancer (28). The present results indicated that aberrant upregulation of FAM83H-AS1 was associated with poor prognosis of patients with ESCC. These studies indicated that FAM83H-AS1 may be widely overexpressed in human cancers and have crucial roles in the pathogenesis of cancers.

To date, only a limited number of studies have explored the oncogenic characteristics of FAM83H-AS1 in human malignancies. Silencing of FAM83H-AS1 decreased the malignant behavior of bladder cancer cells, including proliferation, migration, invasion and cycle arrest progression (25), while activation of MET/EGFR signaling underlined the pro-tumorous roles of FAM83H-AS1 in lung cancer (28). In the present study, genetic interference assays uncovered that inhibition of FAM83H-AS1 expression significantly suppressed the proliferation and migration of ESCC cells, which provided further evidence for the oncogenic role of FAM83H-AS1 in human malignancies. The mechanisms underlying the oncogenic role of FAM83H-AS1 may be complex and tumor 
type-specific, and the downstream targets modulated by FAM83H-AS1 require further investigation.

In conclusion, the present study demonstrated upregulation of FAM83H-AS1 in ESCC. Of note, elevated FAM83H-AS1 expression was associated with shortened survival. However, further in-depth research is warranted to uncover the molecular mechanisms of the proliferative and metastasis-enhancing effects of FAM83H-AS1 in ESCC.

\section{Acknowledgements}

Not applicable.

\section{Funding}

No funding was received.

\section{Availability of data and materials}

The datasets used and/or analyzed during the current study are available from the corresponding author on reasonable request.

\section{Authors' contributions}

JD contributed to the conception of the present study. LB and RW performed the experiments and data analysis. PL contributed to data collection and interpretation, and LB, RW and JD drafted the initial manuscript. All authors have read and approved the final manuscript.

\section{Ethics approval and consent to participate}

All procedures performed involving human participants were in accordance with the ethical standards of the institutional and/or national research committee and with The 1964 Declaration of Helsinki and its later amendments or comparable ethical standards. All cases had complete follow-up information and provided written informed consent. The present study was approved by the Research Ethics Committee of The First Affiliated Hospital of Anhui Medical University (Hefei, China; approval no. Quick-PJ 2020-08-11).

\section{Patient consent for publication}

Not applicable.

\section{Competing interests}

The authors declare that they have no competing interests.

\section{References}

1. Chen W, Zheng R, Baade PD, Zhang S, Zeng H, Bray F, Jemal A, $\mathrm{Yu}$ XQ and He J: Cancer statistics in China, 2015. CA Cancer J Clin 66: 115-132, 2016.

2. Siegel RL, Miller KD and Jemal A: Cancer statistics, 2016. CA Cancer J Clin 66: 7-30, 2016.

3. Oh CM, Won YJ, Jung KW, Kong HJ, Cho H, Lee JK, Lee DH and Lee KH; Community of Population-Based Regional Cancer Registries: Cancer statistics in Korea: Incidence, mortality, survival, and prevalence in 2013. Cancer Res Treat 48: 436-450, 2016.
4. Zeng H, Zheng R, Zhang S, Zuo T, Xia C, Zou X and Chen W: Esophageal cancer statistics in China, 2011: Estimates based on 177 cancer registries. Thorac Cancer 7: 232-237, 2016.

5. Essadi I, Lalya I and Mansouri H: Esophageal carcinoma. N Engl J Med 372: 1470-1471, 2015.

6. Enzinger PC and Mayer RJ: Esophageal cancer. N Engl J Med 349: 2241-2252, 2003.

7. Gao YB, Chen ZL, Li JG, Hu XD, Shi XJ, Sun ZM, Zhang F, Zhao ZR, Li ZT, Liu ZY, et al: Genetic landscape of esophageal squamous cell carcinoma. Nat Genet 46: 1097-1102, 2014.

8. Huang SD, Yuan Y, Zhuang CW, Li BL, Gong DJ, Wang SG, Zeng ZY and Cheng HZ: MicroRNA-98 and microRNA-214 post-transcriptionally regulate enhancer of zeste homolog 2 and inhibit migration and invasion in human esophageal squamous cell carcinoma. Mol Cancer 11: 51, 2012.

9. Ponting CP, Oliver PL and Reik W: Evolution and functions of long noncoding RNAs. Cell 136: 629-641, 2009.

10. Derrien T, Johnson R, Bussotti G, Tanzer A, Djebali S, Tilgner H, Guernec G, Martin D, Merkel A, Knowles DG, et al: The GENCODE $\mathrm{v} 7$ catalog of human long noncoding RNAs: Analysis of their gene structure, evolution, and expression. Genome Res 22: 1775-1789, 2012.

11. Gutschner T and Diederichs S: The hallmarks of cancer: A long non-coding RNA point of view. RNA Biol 9: 703-719, 2012.

12. Sun M and Kraus WL: From discovery to function: The expanding roles of long noncoding RNAs in physiology and disease. Endocr Rev 36: 25-64, 2015.

13. Wapinski $\mathrm{O}$ and Chang HY: Long noncoding RNAs and human disease. Trends Cell Biol 21: 354-361, 2011.

14. Schmitt AM and Chang HY: Long noncoding RNAs in cancer pathways. Cancer Cell 29: 452-463, 2016.

15. Lalevee $\mathrm{S}$ and Feil R: Long noncoding RNAs in human disease: Emerging mechanisms and therapeutic strategies. Epigenomics 7: 877-879, 2015.

16. Batista PJ and Chang HY: Long noncoding RNAs: Cellular address codes in development and disease. Cell 152: 1298-1307, 2013.

17. Ge XS, Ma HJ, Zheng XH, Ruan HL, Liao XY, Xue WQ, Chen YB, Zhang Y and Jia WH: HOTAIR, a prognostic factor in esophageal squamous cell carcinoma, inhibits WIF-1 expression and activates Wnt pathway. Cancer Sci 104: 1675-1682, 2013.

18. Ren K, Li Y, Lu H, Li Z, Li Z, Wu K, Li Z and Han X: Long noncoding RNA HOTAIR controls cell cycle by functioning as a competing endogenous RNA in esophageal squamous cell carcinoma. Transl Oncol 9: 489-497, 2016.

19. Lu C, Yang L, Chen H and Shan Z: Upregulated long non-coding RNA BC032469 enhances carcinogenesis and metastasis of esophageal squamous cell carcinoma through regulating hTERT expression. Tumour Biol: Oct 10, 2016 (Epub ahead of print). doi: 10.1007/s13277-016-5428-9.

20. Chen X, Han H, Li Y, Zhang Q, Mo K and Chen S: Upregulation of long noncoding RNA HOTTIP promotes metastasis of esophageal squamous cell carcinoma via induction of EMT. Oncotarget 7: 84480-84485, 2016

21. Li J, Chen Z, Tian L, Zhou C, He MY, Gao Y, Wang S, Zhou F, Shi S, Feng X, et al: LncRNA profile study reveals a three-lncRNA signature associated with the survival of patients with oesophageal squamous cell carcinoma. Gut 63: 1700-1710, 2014.

22. $\mathrm{Hu} \mathrm{L}$, Wu Y, Tan D, Meng H, Wang K, Bai Y and Yang K: Up-regulation of long noncoding RNA MALAT1 contributes to proliferation and metastasis in esophageal squamous cell carcinoma. J Exp Clin Cancer Res 34: 7, 2015.

23. Thum T and Fiedler J: LINCing MALAT1 and angiogenesis. Circ Res 114: 1366-1368, 2014.

24. Gutschner T, Hammerle M, Eissmann M, Hsu J, Kim Y, Hung G, Revenko A, Arun G, Stentrup M, Gross M, et al: The noncoding RNA MALAT1 is a critical regulator of the metastasis phenotype of lung cancer cells. Cancer Res 73: 1180-1189, 2013.

25. Shan H, Yang Y, Zhu X, Han X, Zhang P and Zhang X: FAM83H-AS1 is associated with clinical progression and modulates cell proliferation, migration, and invasion in bladder cancer. J Cell Biochem 120: 4687-4693, 2019.

26. Lu S, Dong W, Zhao P and Liu Z: IncRNA FAM83H-AS1 is associated with the prognosis of colorectal carcinoma and promotes cell proliferation by targeting the Notch signaling pathway. Oncol Lett 15: 1861-1868, 2018.

27. Yang L, Xu L, Wang Q, Wang M and An G: Dysregulation of long non-coding RNA profiles in human colorectal cancer and its association with overall survival. Oncol Lett 12: 4068-4074, 2016. 
28. Zhang J, Feng S, Su W, Bai S, Xiao L, Wang L, Thomas DG, Lin J, Reddy RM, Carrott PW, et al: Overexpression of FAM83H-AS1 indicates poor patient survival and knockdown impairs cell proliferation and invasion via MET/EGFR signaling in lung cancer. Sci Rep 7: 42819, 2017.

29. Arnes L, Liu Z, Wang J, Maurer C, Sagalovskiy I, Sanchez-Martin M, Bommakanti N, Garofalo DC, Balderes DA, Sussel L, et al: Comprehensive characterisation of compartment-specific long non-coding RNAs associated with pancreatic ductal adenocarcinoma. Gut 68: 499-511, 2019.

30. Zhang F, Wang Y, Sun P, Wang ZQ, Wang DS, Zhang DS Wang FH, Fu JH, Xu RH and Li YH: Fibrinogen promotes malignant biological tumor behavior involving epithelial-mesenchymal transition via the $\mathrm{p}-\mathrm{AKT} / \mathrm{p}-\mathrm{mTOR}$ pathway in esophageal squamous cell carcinoma. J Cancer Res Clin Oncol 143: 2413-2424, 2017.

31. Qi F, Liu X, Wu H, Yu X, Wei C, Huang X, Ji G, Nie F and Wang K: Long noncoding AGAP2-AS1 is activated by SP1 and promotes cell proliferation and invasion in gastric cancer. J Hematol Oncol 10: 48, 2017.
32. Su C, Chen Z, Luo H, Su Y, Liu W, Cai L, Wang T, Lei Y and Zhong B: Different patterns of NF-KB and Notch1 signaling contribute to tumor-induced lymphangiogenesis of esophageal squamous cell carcinoma. J Exp Clin Cancer Res 30: $85,2011$.

33. Han C, Fu Y, Zeng N, Yin J and Li Q: LncRNA FAM83H-AS1 promotes triple-negative breast cancer progression by regulating the miR-136-5p/metadherin axis. Aging (Albany NY) 12: 3594-3616, 2020

34. Huang HZ, Yin YF, Wan WJ, Xia D, Wang R and Shen XM: Up-regulation of microRNA-136 induces apoptosis and radiosensitivity of esophageal squamous cell carcinoma cells by inhibiting the expression of MUC1. Exp Mol Pathol 110: 104278, 2019.

35. Gong YB and Zou YF: Clinical significance of lncRNA FAM83H-AS1 in ovarian cancer. Eur Rev Med Pharmacol Sci 23: 4656-4662, 2019. 